\title{
Residential rural training program in undergraduate medical education: A qualitative evaluation of the impact on doctors and medical students
}

\author{
Johnson, A.R., Rathnakumari, S., Fathima, F. N. \& Joseph, B.
}

\begin{abstract}
Background: Since the last 40 years, first year medical students at St. John's Medical College, Bangalore, India have undergone a residential Rural Orientation Program (ROP). This study aimed to evaluate the impact of ROP on medical students and practicing doctors who have attended this program during undergraduate training.

Methods: A qualitative study was conducted among alumni and medical students of St. John's Medical College, using an open-ended questionnaire sent electronically to assess their perspective of ROP, as well as reflective narratives on their ROP experience. Thematic data analysis was done using inductive coding.

Results: From 287 responses, the main themes identified under Impact of ROP were 'better learning/understanding of Community Medicine', 'benefits in medical career' and 'soft skills development'. We found that ROP is perceived as a unique opportunity for interaction of students with rural communities, a first-hand experience towards understanding rural ways of life, sensitization to the needs of rural people and effective understanding of the basic concepts of community medicine. ROP is reported to have had an impact in terms of enhanced professional skills, basic research skills and soft skills like improved communication abilities and teamwork. It was perceived that ROP helped develop empathy for the underprivileged and was a strong influencer in the decision to commit to two years of rural service.

Conclusion: The ROP has had a highly positive impact on those who participated in it as undergraduate medical students. The success of ROP as a pedagogic strategy in terms of its impact, iterates and emphasises the need for such immersive and experiential learning through residential rural training programs in medical colleges.
\end{abstract}

Key Words: Community-based training, Residential rural training, Medical education, Qualitative evaluation

\section{Introduction}

With two-thirds of the Indian population hailing from rural areas (World Bank, 2018), it is inevitable that a significant proportion of patients, even in city hospitals, come from rural backgrounds. In this context, communitybased, residential rural training programs provide medical students with a unique opportunity to learn first-hand while exploring

\footnotetext{
Department of Community Health,

St. John's Medical College,

Bangalore- 560034,

India

Corresponding Author: Farah Naaz Fathima, Department of Community Health, St. John's Medical College, Bangalore, India.

Email: doc.farah@gmail.com
}

socio-cultural determinants of health in agrarian settings, experiencing rural ways of life and approaching health care holistically.

Ever since 1979, students at St. John's Medical College, Bangalore (SJMC) undergo a Rural Orientation Program (ROP) organized by the Department of Community Health. In its current form, this is a week-long residential program for first year medical students at the Community Health Training Centre (CHTC) Mugalur, located $35 \mathrm{kms}$ from Bangalore City. As part of the ROP curriculum, students use selfdeveloped topic guides to conduct a family and community study, observe and interact with village residents, familiarize themselves with village structure and organizations, rural economics, education, occupations, housing,

DOI: http://doi.org/10.4038/seajme.v14i2.223

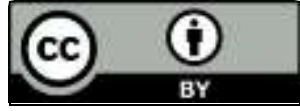

C SEAJME. This is an Open Access article distributed under the terms of the Creative Commons Attribution License (http://creativecommons.org/licenses/by/4.0/), which permits unrestricted use, distribution, and reproduction in any medium, provided the original author and source are credited 
diet, family life, local governance, child rearing and healthcare systems. Students understand difficulties and dilemmas faced by rural folk through a unique simulation exercise called 'Monsoons', which focuses on some of the dynamics of poverty in an imaginary village in India. Students take on the roles of farmers and their families, as well as a money-lender, a development worker and a village 'goonda' or thug. Dependence on the monsoon, cooperation and leadership within the village, the polarisation of rich and poor, the role of money-lender and development worker, effect of irrigation, malnutrition and its consequences, and the pressures of social conformity are some of the issues raised. This game was first developed by John Staley in 1981 (Staley, 1981), but the issues raised during the course of the game are still relevant today. Students also learn about locally available and affordable foods, by purchasing raw food items from the local village market and cooking culturally acceptable, nutritious dietary preparations. They learn to harness available community resources through programs like "child-to-child education" where medical students train school students to teach their classmates and families about common health issues. The community programs, including street play, provide students with a unique health education opportunity with community participation. Presentation and review of daily activities provide a space for introspection and discussion of learnings on the field with applications in primary health care practice. A manual for step-by-step implementation of the ROP has been developed by the Department of Community Health at SJMC, to ensure quality and standardization of instruction (Department of Community Health, 2015).

The objective of this paper is to evaluate the impact of ROP on those who have attended this program as undergraduate medical students at SJMC.

\section{Methods}

A qualitative survey methodology was used in this study. To begin with, key informant interviews (KIIs) were conducted with former heads and senior faculty of the Department of Community Health to understand the origins of the ROP. Thereafter, alumni and medical students of SJMC, who had attended ROP more than one year ago, were invited to participate in the study. A list of alumni from the batch of 1979 onwards (who had attended ROP as undergraduate medical students) and medical students who had completed ROP more than one year ago was obtained from the
SJMC Alumni Association and Academic Section Office respectively, along with their contact details.

A questionnaire via Google Forms was sent by email or WhatsApp to 2400 eligible participants. This included open-ended questions on their perspective of ROP and how it had influenced them. The participants were also asked to write a reflective narrative on their ROP experience, focusing on their learnings from specific activities, whether and how the ROP influenced their career trajectory and the relevance of ROP in their medical education. No word limit was suggested. Consent was built into the Google Form and participants were assured of anonymity.

Ethical clearance was received from SJMC Institutional Ethics Committee prior to commencement of the study (IEC\#18/2018). Participants' names and email IDs were delinked from the data prior to analysis.

Qualitative data thus collected, was exported to Microsoft Excel. The grounded theory method was used for the development of a thematic framework. Inductive coding was done to identify themes and subthemes. (Roberts et al., 2019) Coding was done manually.

\section{Results}

The KIls revealed that the original idea for the ROP stemmed from recommendations of ReOrientation of Medical Education (ROME) Programme, Government of India, 1977 (Poulose et al., 1989). Former heads of department reflected that ROP was initiated to immerse young and impressionable students into rural settings, which would prepare them better for clinical services that they would likely take up in later years. Over the last 40 years, the ROP has evolved, been tweaked in terms of activities and content, but the objective remains unchanged; to orient medical students to conditions prevailing in rural areas, to provide opportunities for students to interact with rural communities and to create students' awareness and understanding regarding the health status and determinants of health in rural areas.

A total of 287 responses were received from alumni and students. Nearly half of the participants had completed ROP more than a decade ago. (Table 1) The main themes identified under Impact of ROP were: 'better learning/understanding of Community Medicine', 'benefits in medical career' and 'soft skills development'. (Fig 1) 
Table 1: Distribution of participants according to Year of admission to MBBS course and No. of years since completion of $\mathrm{ROP}(\mathrm{N}=287)$

\begin{tabular}{ccc}
\hline $\begin{array}{c}\text { Year of admission } \\
\text { to MBBS course }\end{array}$ & $\begin{array}{c}\text { No. of years since completion } \\
\text { of ROP }\end{array}$ & $\mathbf{N}(\%)$ \\
\hline $1979-1988$ & $31-40$ years & $28(9.8)$ \\
\hline $1989-1998$ & $21-30$ years & $36(12.5)$ \\
\hline $1999-2008$ & $11-20$ years & $72(25.1)$ \\
\hline $2009-2018$ & $1-10$ years & $151(52.6)$ \\
\hline
\end{tabular}
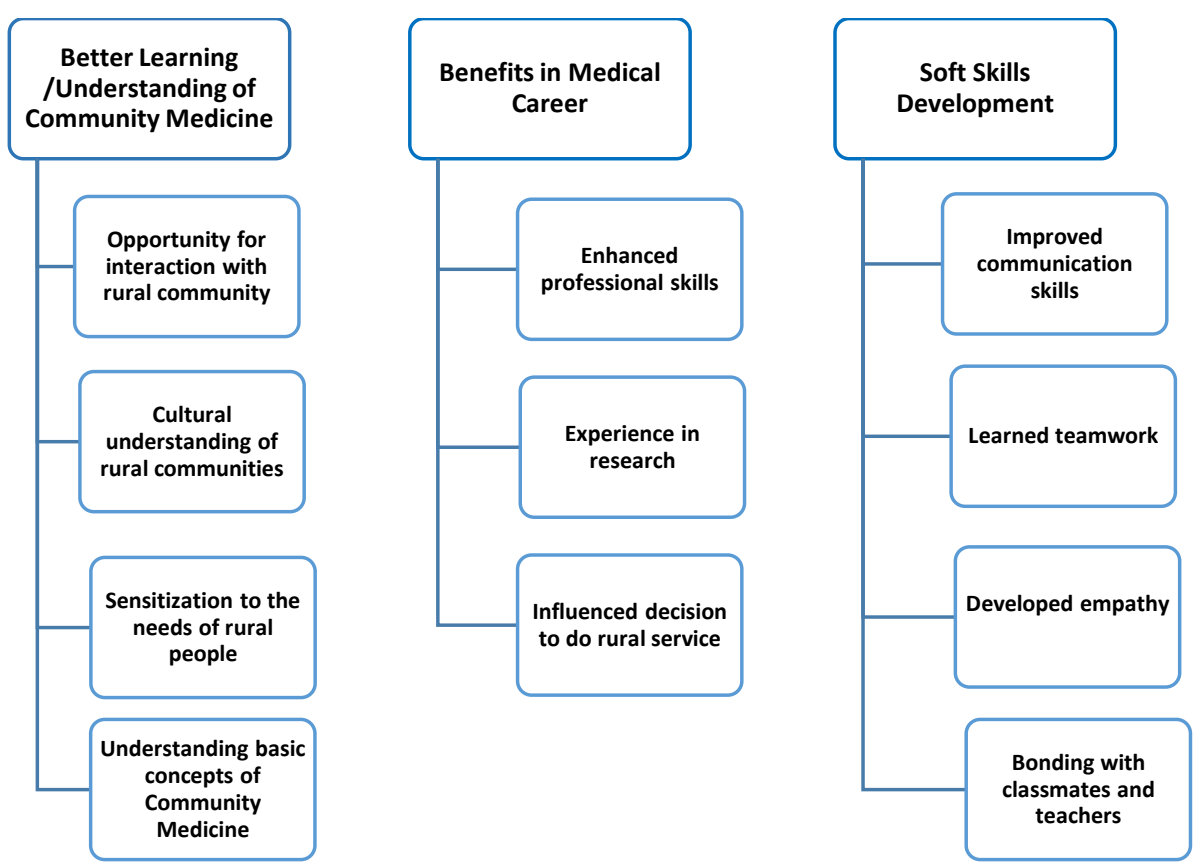

Figure 1: Flow chart depicting Coding Tree with Themes and Sub-themes

\section{Better Learning /Understanding of Community Medicine:}

The sub-themes established were 'opportunity for interaction with rural community', 'cultural understanding of rural communities', 'sensitization to needs of rural people' and 'understanding basic concepts of Community Medicine'.

Opportunity for interaction with rural community: Respondents appreciated the opportunity to interact with different target groups like women, adolescents, village health groups and local leaders. They felt their learning was beyond that provided by theory and practical classes. "...a unique opportunity to interact with the rural community, something we never got from textbooks or lectures." [Alumnus] "...taught me how to interact with underprivileged people, to learn from them" [Medical student, Year 4, male]. For most students, it was the first time they had seen a village, visited a rural family and observed rural way of life. "...growing up in a city, ROP was the first experience in a village. Visiting houses, anganwadi and dairy co-operative, speaking to villagers, walking through fields...all had a huge impact on me as a first-year medical student. It also helped me learn the local language" [Intern, Female]

Better cultural understanding of rural communities: Social dynamics in a village, traditional beliefs and rural way of life was highlighted by the ROP. Rural socio-economic and housing conditions, health-seeking behavior and cultural background to certain traditional practices were some of the learnings 
mentioned. "...l learnt to take social and cultural factors into consideration while treating patients and to think of the economic burden on families" [Alumna, currently doing two-years rural service].

Sensitization to the needs of rural people: ROP gave a first-hand experience of rural life and helped to highlight differences between perceived needs by healthcare personnel and felt needs of the community. This seemed to have been reinforced by the simulation game played at the ROP. "... in a country like India, where most health care facilities are concentrated in cities, it is important to realize how we have collectively failed our villages" [Alumnus]. "...not only interacting with rural communities, but also the farmers' game (Monsoons) was eye-opening...it helped me even when I was doing my rural service" [Alumnus].

Understanding of basic concepts of community medicine: Respondents felt that they were able to understand and experience for themselves previously abstract concepts in community medicine like primary health care, community participation, inter-sectoral coordination, information education and communication. "...concepts like community participation in healthcare, importance of Anganwadi structure in the health system, developing solutions to health problems that are both novel as well as practical and sustainable, were things that I had read in books, but really came to life at ROP. Experiences of educating village folk on health, seeing their houses and getting a feel of their lifestyles, watching community health workers go about their duties with enthusiasm and cooking with village folk really stood out for me" [Alumna]. "...ROP gave me a holistic perspective that made studying from Park's Textbook of Preventive and Social Medicine much easier and logical" [Medical student, Year 4, female].

\section{Benefits in medical career:}

The sub-themes identified were 'enhanced professional skills', 'experience of research', 'influenced decision to do rural service'.

Enhanced professional skills: Family visits helped gain confidence which helped later in patient-interaction in the hospital. Many mentioned that they learnt and practiced the local language during ROP, which helped them during their clinical or internship postings, while some wrote of how they were able to keep in mind socio-cultural aspects of health while caring for their patients. "...ROP experience helped me settle quickly when I did my community health rural posting during internship". [Intern, Female] "...taught me to factor cultural and social norms into the clinical equation, it made me mindful of how hard and basic the lives of some of our patients are and influenced the way I treated my patients" [Alumna, currently doing postgraduation].

Experience in research: Students had their first taste of how to conduct a research study through house-to house surveys and presentation of their findings. "...I understood basics of preparing a questionnaire, data collection, analyzing data and drawing conclusions" [Medical student, Year 3, female].

Influenced decision to do rural service: Some respondents mentioned that ROP had created a sense of responsibility to the community, which made them want to reach out to the unserved. "...ROP made me think that doing rural service was worthwhile" [Alumna]. "ROP played a vital role in my decision to honor my rural service commitment after MBBS" [ Alumnus currently doing rural service]. "...though I am a specialist, I continue to do rural outreach clinics because of my learnings in ROP" [Alumnus]. (Note: Though all medical students at SJMC sign a bond committing to two years of rural service immediately after their internship, some choose to break the bond and pay the penalty amount.)

\section{Soft Skills Development:}

The sub-themes that emerged were 'improved communication skills', 'learned teamwork', 'developed empathy', 'bonding with classmates and teachers'.

Improved communication skills: ROP helped in social interaction with people from a very different background to that of the respondents. It improved their communication skills through different activities like house-to house survey, role playing and community health education programs. "...in a world currently obsessed with social media and mobile phones, I feel ROP helped to build social interaction and communication skills for students like me" [Medical student, Year 4, male]. “... ROP taught me how to interact with underprivileged people, to be more respectful, to treat them better" [Alumna, currently doing postgraduation]

Learned teamwork: Nearly all the activities in ROP help to build team spirit by making students interact and work with each other in small groups. "...learnt to work in a team for the very first time during ROP" [Medical student, Year 3, male], "...not only doctors, but every other team member is essential" [Alumnus], "... 
learnt how to approach a community as a team" [Medical student, Year 3, male].

Developed empathy: Respondents mentioned that seeing villages and the way people live, made them empathize with ground realities and struggles of rural people. "...gave me a better understanding of inequities that exist in health care, particularly across rural-urban divides" [Alumna], "...gave us a clearer vantage point with regards to lives of rural folk of our country. It deepened my empathy towards them. Better understanding of their lifestyle has positively influenced my clinical approach and outlook and has inspired me to serve the underserved to the best of my ability" [Alumna, currently doing rural service].

Bonding with classmates and teachers: Students of SJMC hail from different cultural, social and linguistic backgrounds. ROP was a unique opportunity for them to get to know each other as well as the faculty of Community Health while residing at CHTC, Mugalur. "...great bonding experience for new MBBS students" [Alumnus]. "...we developed a unique bond with all our teachers in Com-Med dept who stayed with us in the village during ROP...we didn't have this connect with other departments during our MBBS course" [Alumnus, currently doing postgraduation].

\section{Discussion}

The new Competency Based Medical Education curriculum prescribed by Medical Council of India for undergraduate medical education also includes Attitude, Ethics and Communication [AETCOM] $(\mathrm{MCl}, 2018)$. This value addition of AETCOM to the curriculum emphasizes on training undergraduates to provide preventive, promotive, and holistic care with compassion. It envisages doctors who will be leaders and members of the health care system with capabilities to collect, synthesize and communicate health data. It seeks to prepare medical students to be communicators with patients, families, colleagues and community as well as develop into professionals who are ethical, responsive and accountable to patients and communities. ROP is aligned with these principles of AETCOM and provides medical students with the ideal opportunities to learn, practice and imbibe AETCOM. We have learnt during this evaluation, that being a community-based rural training program, ROP imparts a value based medical education to undergraduate medical students and inspires and equips them to serve with empathy in medically underserved areas. Respondents believe that ROP enabled them to become better doctors who are sensitive to needs of communities that they work with.

A study in six medical colleges across three states in north India, looking at factors affecting medical students' interest in rural service, suggests that students wish to give back to disadvantaged communities, but often feel illequipped as doctors to do so (Goel et al., 2019). Our study found that ROP inspired medical students to take up rural service and gave them confidence to deal with patients from rural areas. Even in developed nations, where it has become increasingly difficult to find doctors willing to serve in rural areas, medical schools have initiated special programs, such as in California (Eidson-Ton et al., 2016) which includes rural clinical experiences and outreach programs, mentorship for rural elective postings and opportunities for engagement with rural communities. This program has achieved some success in placement of students in primary care residencies in rural areas across USA. A well-organised rural elective placement in a medical school program has been shown to produce positive associations with increased rural service intentions and actual graduate rural employment (Johnson et al., 2018). This has been amply endorsed by the findings of our study. ROP succeeds in its aim of creating doctors who empathise with the underserved, after seeing realities of rural India and experiencing to an extent, challenges faced by rural communities.

A study on empathy and its correlates among medical students in a government medical college, found a significant decline in empathy with rise in semesters (Biswas et al., 2018). Contrarily, our study found that graduates and students credited ROP for having instilled in them empathy for rural and underserved communities, which prompted some to fulfil their commitment to rural service after graduating, or offering to conduct outreach clinics after specialisation in a clinical subject.

Evidence of success of residential rural training programs also comes from the Pacific Immersion Programme in New Zealand (Sopoaga et al., 2017) where medical students are given the opportunity to learn about cultural determinants of health by living with local communities or 'immersion'. The key to this program's success is enabling students to be engaged learners from 'the inside' rather than an 'outsider looking in', which was similarly found in our evaluation of the ROP.

Despite giant strides in information technology, ROP continues to focus on personal 
communication with rural people through triedand-tested methodology like street plays and family study, while incorporating enjoyable and memorable innovations like child-to-child program and simulation games. Though the focus has always been health problems and health needs of rural communities, participants feel greatly benefitted from having gone beyond the theory in their textbooks, to actually being able to connect what they learnt during ROP to their clinical postings in their MBBS course and even later in their clinical practice.

While there are some medical colleges in India, successfully running rural residential training programs like Christian Medical College, Vellore (David, 2005), and Mahatma Gandhi Institute of Medical Sciences, Sewagram (MGIMS, 2019), there is definite scope and need for such programs to be included in formal training of undergraduate medical students, with a view of creating doctors who are attuned to health needs and challenges of underprivileged and underserved communities through an immersive and experiential learning experience.

\section{Limitations:}

- Though participants were assured of anonymity, they may have chosen not to reveal negative feelings and experiences of ROP. Also, there is a chance that students with positive experiences of ROP mostly may have chosen to respond to the survey invitation.

- As the ROP is of one-week duration, there is restriction on the time spent by medical students in having a immersive learning experience in the rural environment, which is a challenge in such programs.

- The lack of faculty point of view in exploring the challenges of running such a program is also a limitation in our study.

\section{Conclusion}

The ROP at St. John's Medical College, Bangalore was found to have had a highly positive impact on those who participated in it as undergraduate medical students. The ROP as a pedagogic strategy has afforded a unique opportunity for interaction of students with rural communities, many of whom experienced this interaction for the first time, leading to a better understanding of rural communities, sensitization to the needs of rural people and effective understanding of the basic concepts of Community Medicine. The ROP was found to have an impact in terms of enhanced professional skills through improved patient care later in their career, as well as providing basic research skills. It also enhanced soft skills among its participants like improved communication and teamwork. It was perceived that ROP helped to developed empathy for the underprivileged and was a strong influencer in the decision to commit to two years of rural service. The success of ROP in terms of its impact, indicates a need for such immersive and experiential learning through residential rural training programs in medical colleges. The lack of faculty point of view and the likelihood of those with positive experiences of ROP mostly responding to the survey invitation may be considered as limitations of this study. However, the reported success of ROP in terms of its impact, indicates a need for such immersive and experiential learning through residential rural training programs in medical colleges.

\section{Acknowledgements}

- Management, St. John's Medical College, Bangalore

- Heads of Department and faculty members of Department of Community Health, St. John's Medical College from 1979 till date.

\section{Conflict of Interest}

There is no conflict of interest.

\section{References}

Biswas, B., Haldar, A., Dasgupta, A., Mallick, N., \& Karmakar, A. (2018) An Epidemiological Study on Empathy and its Correlates: A cross-sectional assessment among medical students of a government medical college of India. Indian Journal of Psychological Medicine, 40, 4, pp.364369.

David, T. (2005) Competency Building Education Programme at Christian Medical College, Vellore. Health Administrator, 17, 1, pp.82-84.

Department of Community Health (2015) Rural Orientation Program: Manual for implementation, St. John's Medical College, Bangalore.

Eidson-Ton, W. S., Rainwater, J., Hilty, D., Henderson, S., Hancock, C., Nation, C. L., \& Nesbitt, T. (2016). Training medical students for rural, underserved areas: A rural medical education program in California. Journal of Health Care for the Poor and Underserved, 27, 4, pp.16741688. 
Goel, S., Angeli, F., Dhirar, N., Sangwan, G., Thakur, K., \& Ruwaard, D. (2019) Factors affecting medical students' interests in working in rural areas in North India-A qualitative inquiry. PloS One, 14, 1, e0210251.

Johnson, G. E., Wright, F. C., \& Foster, K. (2018) The impact of rural outreach programs on medical students' future rural intentions and working locations: a systematic review. BMC Medical Education, 18, 1, pp.196.

MGIMS. Mahatma Gandhi Institute of Medical Sciences (2019) Community Based Medical Education [Online]. MGIMS, Sevagram, Wardha. Available at: https://www.mgims.ac.in/index.php?option= com content\&view $=$ article\&id $=34 \&$ ltemid $=3$ 9 (Accessed: 28 Apr 2020)

$\mathrm{MCl}$. Medical Council of India (2018) Attitude, Ethics and Communication. (AETCOM) [Online]. MCl, New Delhi. Available at: https://www.mciindia.org/CMS/wpcontent/uploads/2020/01/AETCOM_book.p df (Accessed: 20 Jan 2020)
Poulose, K. P., \& Natarajan, P. K. (1989) Reorientation of medical education in India past, present and future. Indian Journal of Public Health, 33, 2, pp.55-58.

Roberts, K., Dowell, A. \& Nie, J. (2019) Attempting rigour and replicability in thematic analysis of qualitative research data; a case study of codebook development. BMC Medical Research Methodology, 19, pp.66.

Sopoaga, F., Zaharic, T., Kokaua, J. \& Covello, S. (2017) Training a medical workforce to meet the needs of diverse minority communities. BMC Medical Education. 17, 1, pp.19.

Staley, J. (1981) Monsoon: A Simulation Game [Online]. SEARCH. Available at: https://msu.edu/ eheilman/iss/simluation $/ \mathrm{m}$ onsoon-edit.pdf (Accessed: 3 Jan 2020)

The World Bank (2018) Rural population: all countries and economies [Online]. World Bank. Available at: https://data.worldbank.org/indicator/SP.RU R.TOTL.ZS (Accessed: 3 Jan 2020) 